\title{
PERCEPÇÃO SOBRE GESTÃO AMBIENTAL DOS GESTORES DE ESCOLAS PÚBLICAS DO TRIÂNGULO MINEIRO
}

Bethania Rosa Defensor - bethaniarosad@gmail.com

Universidade Federal de Uberlândia

Lara Rúbia Borges Silva - borgesrubialara@ gmail.com

Universidade Federal de Uberlândia

Camila Marques Alves Aguiar - camila.aguiiar@ hotmail.com

Universidade Federal de Uberlândia

Luciana Oranges Cezarino - lcezarino@gmail.com

Universidade Federal de Uberlândia 


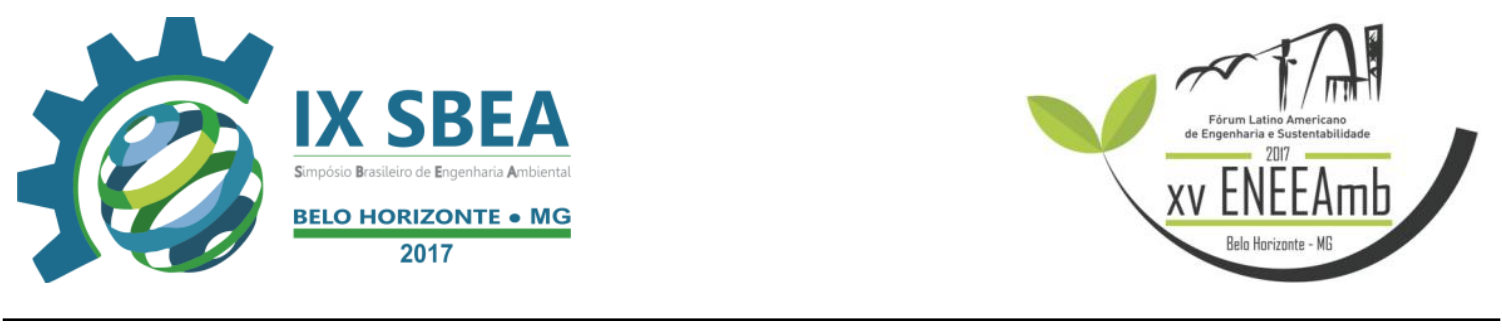

\section{RESUMO}

As escolas são agentes facilitadores para a difusão de valores modificadores do comportamento ambiental individual e social; sendo assim há uma grande necessidade de se desenvolver a temática ambiental nessa instituição, para que jovens e adultos se conscientizem sobre os problemas ambientais que afligem o planeta hoje em dia e sobre o nosso papel como agentes causadores e também solucionadores. A partir desta concepção, ressaltou-se a importância de conhecer o nível de conhecimento dos gestores escolares sobre a temática ambiental e sobre como a sua abordagem é realizada nas escolas. Para obter esses dados, foram desenvolvidos e enviados aos gestores de escolas públicas do Triângulo Mineiro, questionários para analisar de que forma a Gestão Ambiental vem sendo tratada por estas instituições públicas e qual o nível de conhecimento sobre as questões ambientais dos gestores educacionais. Através dos questionários respondidos pelos gestores, inferiu-se que a grande maioria deles acha fundamental que as escolas se preocupem com as questões ambientais. Há diversas políticas publicas que incentivam a prática das questões ambientais nas escolas como a Política Nacional de Educação Ambiental. Mesmo assim, as escolas não aderem essa temática por causa de deficiências da gestão pública como a falta de infraestrutura, de incentivo monetário e ideológico, de vínculos entre instituições, de conhecimento sobre o contexto ambiental, etc. Conclui-se que as escolas e seus gestores têm buscado executar a gestão ambiental da maneira que conseguem, buscando obter o conhecimento necessário e realizando projetos ambientais cabíveis. Mas, infelizmente, ainda esbarram em deficiências que dificultam a agregação da temática ambiental, o que resulta numa menor geração de gestores com consciência ambiental nas empresas e que possuam uma visão de sustentabilidade integrada, podendo atuar na solução dos problemas ambientais.

Palavras-chave: Gestão ambiental, Escolas públicas, Consciência ambiental e sustentável.

\section{INTRODUÇÃO/OBJETIVO}

Diante dos problemas ambientais que afligem a sociedade atualmente, nota-se a necessidade de sensibilizar a sociedade e as futuras gerações sobre o meio ambiente e a 
importância da sustentabilidade na conservação da vida na Terra (SANTOS, 2011. p. 1). Para tal fim, existem no Brasil alguns mecanismos e políticas públicas que apoiam a incorporação da temática ambiental nas instituições como o Plano Nacional de Educação Ambiental (PNEA) e o Plano de Gestão Ambiental.

Um desses mecanismos é a Gestão Ambiental (GA). De acordo com DIAS (2006, p. 83)

A Gestão Ambiental consiste em um conjunto de medidas e procedimentos que permite identificar problemas ambientais gerados pelas atividades da instituição, como a poluição e o desperdício, e rever critérios de atuação (normas e diretrizes), incorporando novas práticas capazes de reduzir ou eliminar danos ao meio ambiente.

A Gestão Ambiental (GA) também está relacionada com a propagação da sustentabilidade, pois visa o uso de práticas que garantam a conservação e preservação da biodiversidade, a reciclagem das matérias-primas e a redução do impacto ambiental das atividades humanas sobre os recursos naturais.

Outro mecanismo é a Educação Ambiental, que segundo a PNEA (LF 9.795/1999), é um componente essencial e permanente à educação nacional e cabe às instituições públicas escolares promover a educação ambiental de maneira integrada aos programas educacionais que desenvolvem, proporcionando desta maneira a formação individual e coletiva de cidadãos que consigam identificar, prevenir e solucionar problemas ambientais (BRASIL, 1999).

Esses mecanismos e políticas públicas, infelizmente, não são eficientemente vigentes e atuantes no Brasil. Um dos motivos é que, atualmente, o avanço rumo a uma sociedade assentada em valores de sustentabilidade é permeado de conflitos e as causas básicas que provocam atividades ecologicamente predatórias. Consequentemente, isto implica a necessidade de estimular uma participação mais ativa da sociedade como uma forma de estabelecer um conjunto socialmente identificado de problemas, objetivos e soluções (JACOBI, 1997; GUIMARÃES, 2001).

Neste sentido, a escola é fundamental na formação de cidadãos perpetuadores de ações sustentáveis na sociedade, onde o desenvolvimento de projetos e práticas sustentáveis relacionadas ao meio ambiente dentro das escolas gera cidadãos 


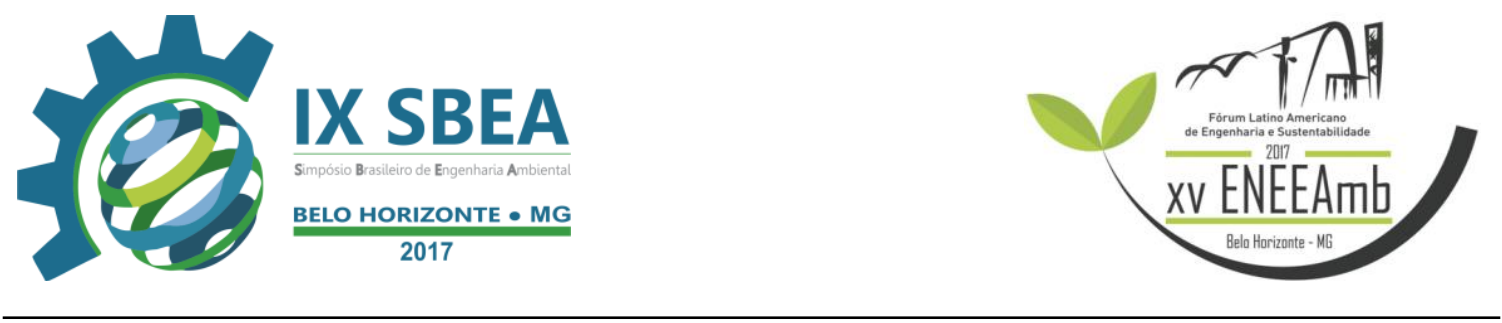

sensibilizados pelas às questões ambientais, fomentando o desenvolvimento de um país ambientalmente equilibrado, fundamentado nos princípios da sustentabilidade, sendo estes cruciais para o enfrentamento dos desafios socioambientais.

Todavia, há poucos estudos na região do Triângulo Mineiro sobre como as escolas discutem questões ambientais e influenciam o engajamento de gestores ambientais dentro das organizações. Portanto, o presente trabalho tem o intuito de contribuir para o diagnóstico da percepção dos gestores educacionais sobre a GA e mostrar como a temática ambiental está sendo desenvolvida em algumas escolas públicas do Triângulo Mineiro.

\section{METODOLOGIA}

A fim de mostrar diferentes visões sobre o que cada escola pública realiza para propagar a GA, foi elaborado um questionário (anexo 1), contendo 18 questões, que foi enviado via e-mail e direcionado à coordenação das escolas. Os endereços eletrônicos das escolas foram obtidos no site oficial do governo de Minas Gerais. A metodologia utilizada para a análise de dados foi a estatística descritiva e análise exploratória, tendo como objetivo resumir, descrever ou apresentar dados (COLLIS; HUSSEY, 2005). Foram obtidas 68 respostas e após a coleta, os dados foram tabulados e alguns dos resultados serão discutidos a seguir.

\section{RESULTADOS E DISCUSSÃO}

Este trabalho mostrou diferentes visões sobre o que cada escola realiza no seu âmbito escolar para propagar a gestão ambiental. Foram obtidas 68 respostas e após a coleta, os dados foram tabulados e os resultados serão discutidos a seguir.

Como resultado, a pesquisa revelou que parte significativa dos gestores que responderam o questionário apresenta uma boa percepção sobre o que é Gestão Ambiental e sua importância no ambiente escolar, além de conhecer a fundamental relação que existe entre Educação Ambiental e Gestão Ambiental. Eles relataram que os principais meios que obtiveram o conhecimento sobre GA foram Cursos, Oficinas e/ou Palestras $(30,9 \%)$ e Internet $(29,4 \%)$. Isso mostra que, em algumas escolas, são desenvolvidos cursos relacionados à temática ambiental para a orientação dos gestores, 


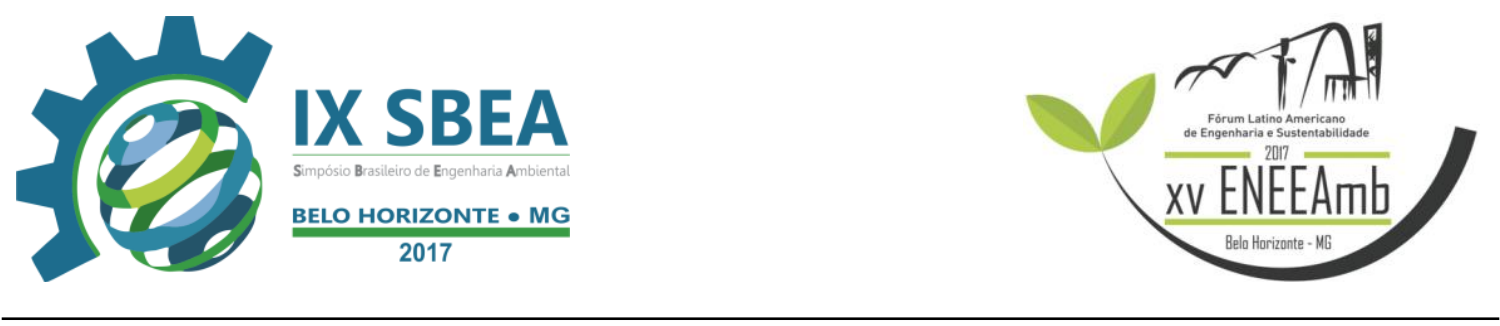

o que é um importante mecanismo para a correta efetivação da gestão ambiental na instituição. Além disso, dentre os 68 gestores que responderam o questionário, 51 gestores concordaram sobre a afirmativa que a escola desempenha um papel relevante na gestão ambiental.

Quando questionados se as escolas não deveriam esperar ajuda do governo para tomar iniciativas ambientais, 39 gestores concordaram totalmente com essa afirmativa, já 5 gestores afirmaram que o governo deveria tomar a iniciativa sobre as questões ambientais nas escolas. Portanto, alguns gestores acreditam que a escola deve ser desvinculada do governo quando a questão é difundir a temática ambiental no âmbito escolar, reconhecendo a importância da discussão dessa área nos primórdios da formação da consciência ambiental nos jovens.

Outro tema discutido foram as possíveis vantagens para a escola ao se engajar em projetos ambientais e se os gestores estariam dispostos a investir financeiramente em melhorias ambientais nas escolas. Dentre os 68 gestores que responderam o questionário, 43 gestores reconhecem que haveria vantagens para a escola e 27 gestores estariam dispostos a investir financeiramente em projetos ambientais na escola.

Com relação ao retorno financeiro em investir em projetos ambientais, 31 gestores presumem que haveria retorno financeiro principalmente por meio da economia de água e energia. Sabendo do importante papel dos alunos sobre a temática ambiental, 36 gestores reconhecem que os alunos iriam perceber melhoras na escola devido a prática de ações ambientais. Além disto, em média 39\% das escolas discordaram que ações ambientais aumentaria a carga de trabalho de seus funcionários.

A respeito do descarte de óleo utilizado nas escolas, 31 gestores informaram que reciclam o óleo para produzir sabão na maioria dos casos, e apenas uma escola informou que despeja o resíduo na pia. Quanto ao gerenciamento dos resíduos sólidos, verificou-se que a maioria das escolas públicas que responderam o questionário, cerca de 60\%, não separam o lixo entre reciclável e não reciclável no ambiente escolar. Sendo o lixo comum, a destinação final dos resíduos mais usada pelos gestores escolares.

Com relação a campanhas de conscientização, 11 gestores informaram que não fazem campanha de Educação Ambiental dentro das escolas. Dentre as que realizam ações, há uma grande variedade de medidas sendo desenvolvidas, desde campanhas de 


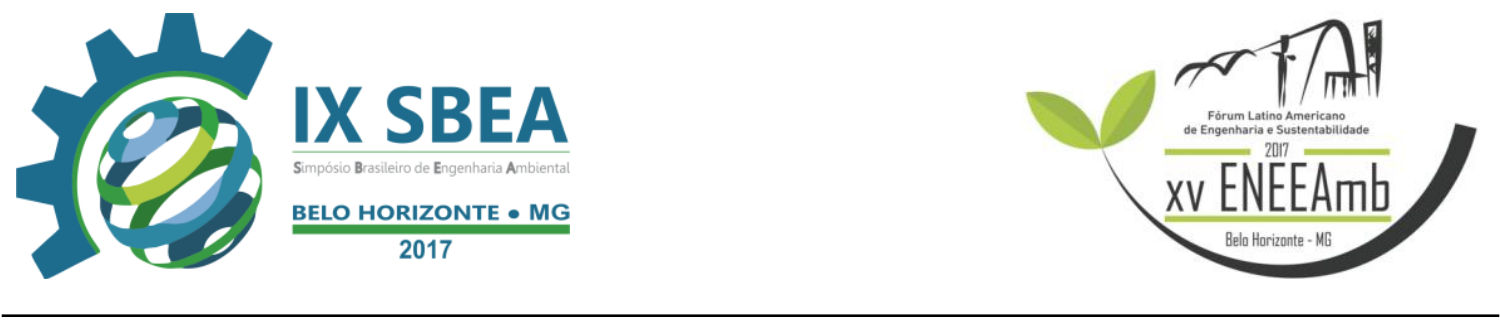

sensibilização a projetos voltados para a área ambiental. Todavia, foram apontadas diversas deficiências e dificuldades pelos gestores para maior implementação de projetos, como a falta de iniciativa, a falta de apoio externo às escolas e a falta de investimento financeiro para a promoção de práticas sustentáveis.

Ao serem questionados sobre a importância de iniciativas focadas na questão ambiental dentro das escolas, os gestores mostraram conhecimento sobre a necessidade de ações voltadas para conscientização e promoção de medidas relacionadas a educação ambiental e preservação do meio ambiente dentro do meio escolar, a fim de formar cidadãos perpetuadores de ações sustentáveis na sociedade.

\section{CONCLUSÕES/RECOMENDAÇÕES}

Esse trabalho mostra que os gestores escolares, na sua maioria, têm uma percepção positiva sobre a importância da GA nas escolas e sabem do papel crucial das escolas na formação da consciência ambiental dos cidadãos. Contudo, as ações analisadas não condizem com o discurso dos gestores, pois estes possuem pouco engajamento e tomada de iniciativas. Dito isso, foram apontadas pelos gestores, diversas deficiências e dificuldades para a realização de projetos sustentáveis, como a falta de uma infraestrutura de gestão adequada, de apoio dos órgãos públicos, de incentivo financeiro e de vínculos externos como o apoio de faculdades públicas. Podese concluir que há um apoio ínfimo a realização de práticas sustentáveis nas escolas; espera-se que haja mais incentivos e iniciativas no futuro por parte dos órgãos públicos, gestores escolares e sociedades para que as questões ambientais não fiquem reclusas do meio escolar. Recomendam-se mais estudos sobre como a escola influencia a consciência ambiental de seus alunos e envolvidos, e como essa tomada de consciência proporciona uma sociedade mais sustentável.

\section{REFERÊNCIAS BIBLIOGRÁFICAS}

BRASIL. Política Nacional de Educação Ambiental (Lei n ${ }^{\circ}$ 9.795, de 27 de abril de 1999). Brasilia, DF: Senado Federal, 1999.

COLLIS, J.; HUSSEY, R. Pesquisa em administração: um guia prático para alunos de graduação e pós-graduação. 2. ed. Porto Alegre: Bookman, 2005. 
DIAS, G. F. Educação e Gestão Ambiental. São Paulo: Gaia, 2006.

JACOBI, P.R. Meio ambiente urbano e sustentabilidade: alguns elementos para a reflexão. In: CAVALCANTI, C. (Org.). Meio ambiente, desenvolvimento sustentável e políticas públicas. São Paulo: Cortez, 1997.

SANTOS, D. A.; SILVA, L. P. M. Diagnóstico e Percepção dos Escolares sobre Projetos Ambientais. In: II SEAT - SIMPÓSIO DE EDUCAÇÃO AMBIENTAL E TRANSDISCIPLINARIDADE. UFG / IESA / NUPEAT - Goiânia, 2011. 
Anexo 1

\section{Diagnóstico Ambiental de Gestão de Serviços}

Esse questionário é um trabalho de extensão desenvolvido por uma equipe de alunos proveniente dos cursos de Engenharia Ambiental, Saúde Ambiental e Administração da UFU, orientado pela a professora Luciana Cezarino.

*Obrigatório

1.

Endereço de e-mail

\section{Questionário voltado para as Escolas}

Escolha a melhor definição para Gestão Ambiental: *

Marcar apenas uma oval.

A gestão ambiental é entendida como sendo "as diretrizes e atividades

administrativas e operacionais realizadas objetivando obter efeitos positivos sobre o meio ambiente, quer reduzindo os danos causados pelas ações humanas, quer evitando que eles surjam". (Barbieri, 2009)

Em função da separação da propriedade (principal/proprietário) e do controle (agente/gestor) da empresa, ocorrem profundas mudanças na forma de gerenciá-la, pois os gestores tendem a considerar não apenas o interesse do proprietário, mas também seus próprios interesses na tomada de decisões (BIANCHI, 2005).

"Qualquer comportamento no qual uma pessoa pretende tirar uma desonesta vantagem em cima de outra" (HS Moura - 2004)

3

Onde você ficou sabendo sobre gestão ambiental? *

Marcar apenas uma oval.

TV;

Internet;

Jornais ou revistas;

Amigos ou família;

Cursos, Oficinas e/ou Palestras:

Outro:

\section{Nível de importância da Gestão Ambiental}

4.

As escolas tem um papel relevante na gestão ambiental. *

Marcar apenas uma oval.

$\begin{array}{lllllll}1 & 2 & 3 & 4 & 5 & \\ \text { Discordo totalmente } & \square & & & & & \end{array}$

5

As escolas não devem esperar ajuda do governo para tomar iniciativas ambientais.

Marcar apenas uma oval.

Discordo totalmente $\square$

IX Simpósio B rasileiro de Engenharia Ambiental, XV Encontro Nacional de Estudantes de 
Eu me preocupo com o meio ambiente. *

Marcar apenas uma oval,

$\begin{array}{llllll}1 & 2 & 3 & 4 & 5 & \\ \text { Discordo totalmente } & \square & & & & \end{array}$

Vejo vantagens para meu negócio ao me engajar em projetos ambientais. *

Marcar apenas uma oval.

$\begin{array}{lllllll} & 1 & 2 & 3 & 4 & 5 & \\ \text { Discordo totalmente } & & & & \\ & \longrightarrow & & \end{array}$

8.

Estaria disposto a investir financeiramente em melhorias ambientais no meio negócio. *

Marcar apenas uma oval.

Discordo totalmente $\square \square$ Concordo totalmente

Vejo retorno financeiro em investir em projetos ambientais. *

Marcar apenas uma oval.

$\begin{array}{lllllll} & 1 & 2 & 3 & 4 & 5 & \\ \text { Discordo totalmente } \square & \square & & & & & \end{array}$

Meus clientes perceberiam melhoras no meu negócio com ações ambientais. * Marcar apenas uma oval.

Discordo totalmente $\square \longrightarrow$ Concordo totalmente

A imagem do meu negócio melhoraria com projetos ambientais. *

Marcar apenas uma oval.

$\begin{array}{lllllll} & 1 & 2 & 3 & 4 & 5 & \\ \text { Discordo totalmente } & \square & \square & & & & \end{array}$

Investir em projetos ambientais aumentaria a carga de trabalho dos meus funcionários.

Marcar apenas uma oval.

Discordo totalmente $\square \longrightarrow$ Concordo totalmente

Projetos ambientais podem motivar meus funcionários. *

Marcar apenas uma oval.

Discordo totalmente $\square \longrightarrow$ Concordo totalmente

\section{O que você já faz?}

IX Simpósio B rasileiro de Engenharia Ambiental, XV Encontro Nacional de Estudantes de 
Como você faz o descarte do óleo utilizado? *

Marcar apenas uma oval.
$\bigcirc \mathrm{Pia}$
Lixo comum
Reciclado
Vendo
Reutilizo
Outro:

15.

Separo o lixo entre reciclável e não reciclável dentro da empresa? *

Marcar apenas uma oval.
$\int \operatorname{Sim}$
Não

16.

Qual a destinação dos restos orgânicos (comida, plantas, resíduos de higiene pessoal)?*

17.

Vocês fazem campanhas de conscientização de seus clientes? Quais? *

18

Qual o seu nivel de interesse de se engajar nos projetos: Escala de Engajamento (0 a 5 - sendo 0 nenhum interesse até 5 máximo interesse). *

Marcar apenas uma oval por linha.

Sesconheço o
Seletiva,
Economia de Água;
Economia de Energia;
Compostagem;
Educação ambiental;
Reciclagem
Dimininuiçãão da Poluição
(atmosférica, visual, auditiva);
Prevenção de Contaminação e
Epidemias.

Em sua opinião, qual a iniciativa mais importante da gestão ambiental. Por quê? * 